\title{
Percepção e atualidade em Modernidade Líquida, de Zygmunt Bauman
}

BAUMAN, Zygmunt. Modernidade líquida. Tradução Plínio Dentzien. Rio de Janeiro: Zahar, 2001.

\section{Ana Lúcia Moura Novais'}

'Instituto Sumaré de Educação Superior, São Paulo - Brasil. E-mail: analucianovais@gmail.com

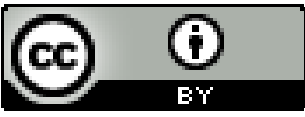

Educação: teoria e prática, Rio Claro, SP, Brasil - eISSN: 1981-8106

Está licenciada sob Licença Creative Common

A proposta desta resenha não é apenas apresentar considerações gerais sobre a obra Modernidade Líquida, de Zygmunt Bauman, publicada em 2001. Mais do que isto é refletir sobre a apurada percepção deste autor sobre os rumos das sociedades modernas e como seu modus vivendi e modus operandi refletem alterações significativas em relação ao próprio indivíduo e sua interação com os diferentes grupos. Bauman (2001) apresenta considerações sobre a modernidade do ponto de vista de sua fluidez, referente à capacidade de sofrer constante mudança e, assim como os líquidos, em tal condição não suporta uma força deformante quando imóvel, o que certamente aconteceria com algo de propriedade sólida. A ideia de leveza, condição fluida atribuída à modernidade, encontra-se bem detalhada no prefácio, que logo no início menciona a definição de fluidos da Enciclopédia britânica, a qual é em seguida descrita pelo autor, em linguagem simples, quanto ao fato de os líquidos, diferentemente dos sólidos, não fixarem o espaço nem prenderem o tempo. Observa-se que o tempo tem papel importante para os líquidos, visto que por conterem fluidez, movem-se com facilidade, escorrem, vazam, transbordam, inundam. Ao contrário dos sólidos não são facilmente contidos, isto é, podem contornar obstáculos, invadir caminhos. Quando os líquidos encontram os sólidos, estes permanecem na mesma condição, mas sofrem alterações, uma vez que ficam molhados ou até mesmo encharcados. Esse movimento dos líquidos, essa fluidez, que lhes é inerente, é associada à noção de leveza. Sólidos, por sua vez, são tidos como pesados, rígidos.

A modernidade como possibilidade de causar derretimento dos sólidos não se limita a uma visão metafórica; a expressão "derreter os sólidos" foi mencionada por Karl Marx e Friedrich Engels (1999) no Manifesto comunista, como se observa no excerto a seguir:

... Essa revolução contínua da produção, esse abalo constante de todo o sistema social, essa agitação permanente e essa falta de segurança distinguem a época burguesa de todas as precedentes. Dissolvem-se todas as 
relações sociais antigas e cristalizadas, com seu cortejo de concepções e de ideias secularmente veneradas; as relações que as substituem tornam-se antiquadas antes de se ossificar. Tudo que era sólido e estável se esfuma, tudo o que era sagrado é profanado, e os homens são obrigados finalmente a encarar com serenidade suas condições de existência e suas relações recíprocas. (MARX; ENGELS, 1999, p. 12, destaques em itálicos nossos)

Observa-se, no trecho citado, que há ênfase no movimento gerado pela ideia de revolução, pelas transformações na sociedade que levam a essa questão de que o que era sólido se desmancharia no ar. Na visão de Bauman (2001) a profanação do sagrado, citada no Manifesto comunista, representa um destronamento do passado, um repúdio à tradição, havendo uma destruição do que era considerado sólido, havendo, assim, um processo de liquefação.

$\mathrm{Na}$ sequência da argumentação, mencionam-se algumas circunstâncias em que há o derretimento dos sólidos: transformações de ordem econômica, mudanças nas sociedades, que conseguiam a seu tempo renovar sua ordem, rever seus processos, sentirem-se mais livres. $\mathrm{O}$ derretimento dos sólidos torna-se, então, um traço permanente da modernidade, adquirindo novo sentido e, acima de tudo, redirecionado para um novo alvo, cujo efeito foi a dissolução de forças que poderiam ter mantido a questão da ordem.

Em relação à época atual, Bauman afirma que a

...nossa é, como resultado, uma versão individualizada e privatizada da
modernidade, e o peso da trama dos padrões e a responsabilidade pelo
fracasso caem principalmente sobre os ombros dos indivíduos. Chegou a vez
da liquefação dos padrões de dependência e interação. Eles são agora
maleáveis a um ponto que as gerações passadas não experimentaram e nem
poderiam imaginar; mas, como todos os fluidos, eles não mantêm a forma
por muito tempo. Dar-lhes forma é mais fácil que mantê-los nela. Os sólidos
são moldados para sempre. Manter os fluidos em uma forma requer muita
atenção, vigilância constante e esforço perpétuo - e mesmo assim o sucesso
do esforço é tudo menos inevitável. (BAUMAN, 2001, p. 14-15)

Como se observa, diferentemente da maneira como Marx e Engels trataram do derretimento dos sólidos, não se trata aqui das mudanças geradas pela revolução, pela consciência de classe, pelas transformações de caráter diversificado que impulsionaram o movimento, o advento da modernidade. Bauman traz em sua discussão o impacto da modernidade líquida, da fluidez dessa modernidade que não para, é contínua, disforme, para a condição do indivíduo.

A fim de se ter uma noção a respeito da estrutura geral da obra, apresentam-se, a seguir, considerações gerais sobre os assuntos desenvolvidos nos capítulos. O primeiro capítulo, "Emancipação", inicia-se com uma citação de Herbert Marcuse, na qual afirma que 
após três décadas da Segunda Guerra Mundial, o problema a ser enfrentado é a necessidade de se libertar de uma sociedade baseada no desenvolvimento de necessidades materiais e culturais do homem; pressupõe a libertação de uma sociedade que tem a falta de uma base de massas para se libertar. Isso significa que poucas pessoas desejavam ser libertadas e até mesmo muito pouco inclinadas a fazer isso. A discussão sobre a liberdade é o grande assunto deste capítulo e Bauman recorre a diferentes autores, que analisam esse tema, e à visão e desejo dos indivíduos em relação à ideia de ser ou de sentir-se livre. Para tanto, inicia uma distinção entre liberdade subjetiva e objetiva; a primeira seria a sensação de algo como relativo à liberdade, mas de fato não o é, algo que está longe se ser objetivamente satisfatório. Dá-se início, então, a uma indagação; se a liberdade é uma bênção ou uma maldição.

Adiante, Bauman afirma que a sociedade do século XXI não é menos moderna que a do século XX; apenas é moderna de um jeito diferente.

O que a faz tão moderna como era mais ou menos há um século é o que distingue a modernidade de todas as outras formas históricas do convívio humano: a compulsiva e obsessiva, contínua, irrefreável, insaciável sede de destruição criativa (ou de criatividade destrutiva, se for o caso: de 'limpar o lugar' em nome de um 'novo e aperfeiçoado' projeto; de 'desmantelar', 'cortar', 'defasar', 'reunir', ou 'reduzir, tudo isso em nome da maior capacidade de fazer o mesmo no futuro - em nome da produtividade ou da competitividade." Revela-se, a partir daí, a distinção entre dois tipos de modernidade: a sólida e a líquida. Nesse processo intenso da modernidade líquida ser "moderno passou a significar, (...), ser incapaz de parar e ainda menos capaz de ficar parado. Movemo-nos e continuaremos a nos mover não tanto pelo 'adiamento da satisfação', como sugeriu Max Weber, mas por causa da impossibilidade de atingir a satisfação: o horizonte da satisfação, a linha de chegada do esforço e o momento da autocongratulação tranquila movem-se rápido demais. A consumação está sempre no futuro, e os objetivos perdem sua atração e potencial de satisfação no momento de sua realização, se não antes. Ser moderno significa estar sempre à frente de si mesmo, num Estado de constante transgressão. (BAUMAN, 2001, p. 37).

Essencialmente, o que marca essa fase de modernidade são as sociedades de indivíduos, isto é, há um processo intenso de individualização, em que este termo se apresenta de maneira diferente de um século atrás. Em linhas gerais, individualização consiste em transformar a identidade humana de um dado em uma tarefa e arcar com a responsabilidade de dar cabo a essa tarefa, bem como seus efeitos. Bauman reforça essa reflexão ao retomar uma frase célebre de Jean-Paul Sartre, em que não bastava nascer burguês: era preciso viver como burguês. A característica da vida moderna seria tornar-se o que já é.

O segundo capítulo está centrado no tema da "Individualidade" e tem como epígrafe uma citação de Lewis Carroll, autor de Alice no País das Maravilhas e Alice no País dos Espelhos. Anuncia-se pela epígrafe a extensão do princípio de agilidade, velocidade na modernidade em sua fase líquida. As referências literárias continuam; no início, Bauman faz 
menção às obras Admirável mundo novo, de Aldous Huxley, e 1984, de George Orwell. Em ambas as obras, dadas as especificidades de enredo e propostas, compartilha-se o pressentimento de um mundo muito controlado em que a liberdade individual fica reduzida a nada ou a quase nada, pois as pessoas são treinadas a seguir ordens e rotinas estabelecidas. A partir daí, começa-se a discutir a diferença entre capitalismo pesado e capitalismo leve.

Capitalismo pesado tem o modelo fordista como parâmetro: uma separação clara entre projeto e execução, iniciativa e atendimento a comandos, liberdade e obediência, ou seja, uma engenharia voltada à ordem.

O fordismo era a autoconsciência da sociedade moderna em sua fase
"pesada", "volumosa", ou "imóvel" e "enraizada", "sólida". Nesse estágio de
sua história conjunta, capital, administração e trabalho estavam, para o bem e
para o mal, condenados a ficar juntos por muito tempo, talvez para sempre -
amarrados pela combinação de fábricas enormes, maquinaria pesada e força
de trabalho maciça. (...) O capitalismo pesado era obcecado por volume e
tamanho, e, por isso, também por fronteiras, fazendo-as firmes e
impenetráveis. O gênio de Henry Ford foi descobrir o modo de manter os
defensores de sua fortaleza industrial dentro dos muros - para guardá-los da
tentação de desertar ou mudar de lado. (BAUMAN, 2001, p. 69)

$\mathrm{Na}$ citação anterior, nota-se que no capitalismo pesado, os trabalhadores estão fixados ao local em que trabalham. No capitalismo leve, há mudanças. O capital viaja leve, apenas com bagagem de mão, que inclui pasta, telefone celular e notebook. Entretanto, o trabalho permanece tão imobilizado quanto no passado: mas o lugar perdeu a solidez dos tempos passados.

Ainda sobre as diferenças entre capitalismo pesado e capitalismo leve, Bauman afirma que o capitalismo pesado representava um mundo no estilo fordista marcado por rotinas e regulação exercida por supervisores, tudo em prol do incremento à produtividade e atendimento de metas pré-estabelecidas. Já, no capitalismo leve, não houve o fim das autoridades, nem elas se tornaram dispensáveis; apenas passou a haver um número maior de autoridades, com permanência por tempo reduzida e sem o caráter de exclusividade à autoridade, tal como havia no capitalismo pesado.

Além das diferenças nas relações de trabalho nos modos do capitalismo pesado e do capitalismo leve, a parte final do segundo capítulo trata da problemática do desejo individual canalizado para a esfera do consumo: certamente a grande crítica de Bauman em relação à modernidade em sua fase líquida; as consequências da compulsão, do desejo desenfreado pelo consumo.

O terceiro capítulo descreve a relação tempo/espaço no contexto da modernidade. $\mathrm{Na}$ parte inicial traçam-se considerações sobre os diferentes espaços e fins a que foram destinados e aqui também se reitera a crítica ao consumo pelos lugares determinados à intensificação das 
operações compulsivas de compra de produtos. Entretanto, o que realmente se destaca neste capítulo é a diferenciação entre modernidade pesada e modernidade leve.

Sobre modernidade pesada, Bauman assim se refere:

A modernidade pesada foi a era da conquista territorial. A riqueza e o poder estavam firmemente enraizados ou depositados dentro da terra - volumosos, fortes e inamovíveis como os leitos de minério de ferro e de carvão. Os impérios se espalhavam, preenchendo todas as fissuras do globo: apenas outros impérios de força igual ou superior punham limites à sua expansão.

Na conquista do espaço, o tempo tinha que ser flexível e maleável, e acima de tudo tinha que poder encolher pela crescente capacidade de "devorar espaço" de cada unidade: dar a volta ao mundo em 80 dias era um sonho atraente, mas ser capaz de fazê-lo em oito dias era infinitamente mais atraente. (BAUMAN,2001, p. 133 e 134)

A relação entre tempo e espaço na modernidade pesada está ligada à rotinização, demarcação. Tempo e espaço são controlados e possuídos apenas quando ocorre tal controle. $\mathrm{Na}$ modernidade leve, era do software, uma grande mudança ocorre nesta questão do tempo/espaço. Partes do espaço podem ser alcançadas a qualquer momento. Dada a complexidade desta ideia, vale retomar o próprio raciocínio de Bauman a esse respeito:

Se todas as partes do espaço podem ser alcançadas a qualquer momento, não há razão para alcançar qualquer uma delas num dado momento e nem tampouco razão para se preocupar em garantir o direito de acesso a qualquer uma delas. Se soubermos que podemos viajar a um lugar em qualquer momento que quisermos, não há urgência em visitá-lo nem em gastar dinheiro em uma passagem válida para sempre. Há ainda menos razão para suportar o gasto da supervisão e administração permanentes, do laborioso e arriscado cultivo de terras que podem ser facilmente ocupadas e abandonadas conforme interesses de momento e "relevâncias tópicas". (BAUMAN, 2001, p. 137)

No quarto capítulo, cujo título é "Trabalho", também se articula o assunto nos modos da modernidade sólida e da modernidade líquida. Na modernidade sólida, novamente o Fordismo é retomado: fase do capitalismo pesado em que os trabalhadores dependiam do emprego para a sobrevivência, assim como o capital dependia deles para reprodução e crescimento. O local de trabalho tinha espaço pré-determinado, fixo. Segundo Bauman, capital e trabalho foram postos face a face pela transação de compra e venda: a fim de que permanecessem vivos, cada qual deveria se manter em forma para prosseguir tal transação. $\mathrm{Na}$ 
modernidade líquida, há fortes mudanças em relação ao trabalho: ele se torna de curto prazo, em que também pode ser realizado em diferentes espaços, até virtuais, pelo uso de tecnologia, de internet. Entretanto, agilidade e insegurança, quanto ao tempo de permanência na função, acompanham o trabalhador da fase da modernidade líquida.

Finalmente, o quinto capítulo, "Comunidade", é entendido por Bauman como uma solução para o processo intenso de individuação das sociedades da modernidade líquida. É a esperança de que os indivíduos reencontrem seu equilíbrio na sua integração com a sociedade, desvencilhando-se da busca desenfreada por itens de consumo que até agora constituem seus referenciais de valores e de identificação e que para tanto se movem para renovar tais operações de consumo.

Apesar de toda a crítica ao forte processo de individuação, marcante na modernidade líquida, Bauman demonstra-se esperançoso por acreditar que em algum momento haverá um sentimento de angústia em grande parte dos indivíduos, pelo grande volume de responsabilidades individuais e pelo aumento da fragilidade dos laços humanos, os quais certamente serão buscados por eles, desejados talvez como outra dimensão de desejo, de realização, uma perspectiva de resgate de interações mais consistentes, que promovam a volta da sensação de sentir-se seguro. Talvez isso seja uma visão idílica, até mesmo "ingênua" por parte de Bauman, apesar de toda sua erudição, seu esclarecimento e olhar crítico nas transformações das sociedades ao longo dos tempos, mas pode ser também a determinação de uma crença de que as sociedades de indivíduos têm limites e que podem vir a promover nova fluidez, nova torrente de movimentos na modernidade já tão liquefeita, tão dispersa e disforme.

\section{Referências}

BAUMAN, Z. Modernidade líquida. Tradução Plínio Dentzien. Rio de Janeiro: Zahar, 2001.

MARX, K.; ENGELS, F. Manifesto comunista (1848). Edição Ridendo Castigat Mores. Versão para eBook eBooks.com. Fonte digital RocketEdition de 1999, a partir de html de www.jahr.org. (versão em .pdf).

Recebido em: 03/07/2015

Aprovado para publicação em: 09/08/2016

Publicado em: 31/08/2016 